\title{
Predicting the distribution of the scyphomedusa Chrysaora quinquecirrha in Chesapeake Bay
}

\author{
M. B. Decker ${ }^{1, *}$, C. W. Brown' ${ }^{2}$ R. R. Hood $^{3}$, J. E. Purcell ${ }^{4}$, T. F. Gross ${ }^{5}$, \\ J. C. Matanoski ${ }^{3,6}$, R. O. Bannon ${ }^{7}$, E. M. Setzler-Hamilton ${ }^{8, \mathrm{~T}}$ \\ ${ }^{1}$ Department of Ecology and Evolutionary Biology, Yale University, New Haven, Connecticut 06520, USA \\ ${ }^{2}$ National Oceanic and Atmospheric Administration, Cooperative Institute of Climate Studies, University of Maryland, \\ College Park, Maryland 20742-2465, USA \\ ${ }^{3}$ Horn Point Laboratory, University of Maryland Center for Environmental Science, PO Box 775, Cambridge, \\ Maryland 21613, USA \\ ${ }^{4}$ Shannon Point Marine Center, 1900 Shannon Point Road, Anacortes, Washington 98221, USA \\ ${ }^{5}$ Chesapeake Bay Research Consortium, 645 Contees Wharf Rd., Edgewater, Maryland 21037, USA \\ ${ }^{6}$ New Mexico State University-Alamogordo, 2400 North Scenic Drive, Alamogordo, New Mexico 88310, USA \\ ${ }^{7}$ University of Rhode Island, Graduate School of Oceanography, Box 200, South Ferry Road, Narragansett, \\ Rhode Island 02882, USA \\ ${ }^{8}$ Chesapeake Biological Laboratory, University of Maryland Center for Environmental Science, PO Box 38, \\ Solomons, Maryland 20688, USA
}

\begin{abstract}
Jellyfish blooms are important events controlling plankton dynamics in coastal waters worldwide, yet factors that influence bloom development are not well understood. We used the scyphomedusa Chrysaora quinquecirrha as a model to examine physical factors that control jellyfish populations and to develop an ecological forecasting system. Over 700 in situ observations collected from Chesapeake Bay and its tributaries during 1987-2000 were used to develop habitat models that predict the probability of occurrence and the likely concentration of medusae as a function of seasurface temperature and salinity. Medusae were found within a relatively narrow range of temperature $\left(26\right.$ to $\left.30^{\circ} \mathrm{C}\right)$ and salinity (10 to 16$)$. Regression analyses reveal that a combination of temperature and salinity is a significant predictor of medusa occurrence. Assessments of the predictive performance of these models using medusae and environmental data collected at independent survey sites $(\mathrm{n}=354)$ indicated that model-predicted medusa occurrence and concentration correspond well with observations. Our models can be forced with near-real time and retrospective estimates of temperature and salinity to generate probability of occurrence maps of $C$. quinquecirrha medusa presence and abundance in order to better understand how this top predator varies in space and time, and how this species could potentially affect energy flow through the Chesapeake Bay system.
\end{abstract}

KEY WORDS: Gelatinous zooplankton $\cdot$ Scyphozoa $\cdot$ Jellyfish $\cdot$ Temperature $\cdot$ Salinity $\cdot$ Climate Predictive model $\cdot$ Forecasting $\cdot$ Nowcasting

\section{INTRODUCTION}

Jellyfish blooms are common occurrences in many coastal habitats and are important events controlling plankton dynamics in these systems (Purcell et al. 2001). In addition, high concentrations of jellyfish have been linked to economic losses in tourism (due to stinging; e.g. Schultz \& Cargo 1969, 1971), commercial fishing (by clogging fishing nets; e.g. Hay et al. 1990, Graham et al. 2003) and energy production (from blocking power plant water intakes; Matsueda 1969, Yasuda 1988, Rajagopal et al. 1989, Matsumura et al. 2005). Evidence has shown increases in jellyfish populations in various locations (Anderson \& Piatt 1999, Brodeur et al. 1999, Mills 2001, Sullivan et al. 2001) and so their impacts are probably increasing. The 
causes of these fluctuations are not well understood. Increasing bloom frequency and extent may be linked to climatic (reviewed in Purcell 2005) and/or anthropogenic effects (Arai 2001, Parsons \& Lalli 2003), and understanding these linkages will be required to predict blooms in the future.

Multiple interacting physical and biological factors lead to the development and persistence of plankton blooms. Information on some of these factors is increasingly accessible in near-real time from geographic databases, hydrodynamic models, and satellite sensors. The capability to assess pertinent environmental parameters in near-real time offers the potential to predict biotic events if the specific environmental conditions associated with their occurrence are known. We used the scyphomedusa Chrysaora quinquecirrha as a model to examine processes that control jellyfish populations and to develop an ecological forecasting system. C. quinquecirrha is an ideal target species for ecological forecasting because distribution data have been collected over many years and the primary factors that control its occurrence (temperature and salinity) can be predicted with models. By developing these capabilities, we improve our understanding of the factors that influence blooms of gelatinous predators and we can determine how these blooms influence the Chesapeake ecosystem. This, in turn, can help guide current multi-species management efforts. Moreover, the approach used here can be applied to other plankton species, such as harmful algal blooms.

Chrysaora quinquecirrha medusae are important in the ecology of Chesapeake Bay. They can reach very high concentrations in summer, particularly in the tributaries where concentrations of $16 \mathrm{~m}^{-3}$ have been measured (Purcell et al. 1994a). This stinging jellyfish occurs in such great abundance that methods were evaluated to control their population sizes (Schultz \& Cargo 1969). In particular, the medusae are extremely important to plankton dynamics due to their high trophic position in the Chesapeake food web (Baird \& Ulanowicz 1989). The medusae consume significant proportions of copepods (Purcell 1992) and of bay anchovy Anchoa mitchilli eggs and larvae in Chesapeake Bay (Purcell et al. 1994a). As possible competitors for zooplankton prey with bay anchovy A. mitchilli (in Purcell 1992), which is an important food for striped bass Morone saxatilis, bluefish Pomatomus saltatrix and other species, medusae could have indirect impacts on commercially important fish populations. C. quinquecirrha also plays an important role as a predator of Mnemiopsis leidyi ctenophores, and can control ctenophore populations in parts of Chesapeake Bay (Purcell \& Cowan 1995, Purcell \& Decker 2005), where the medusae reduced ctenophore abundance, and copepod numbers increased (Feigenbaum \& Kelly
1984, Purcell \& Decker 2005). Thus, predation by C. quinquecirrha medusae has important and complex effects on the food web of Chesapeake Bay.

The medusa stage of Chrysaora quinquecirrha occurs seasonally in Chesapeake Bay. By a process called strobilation, young medusae (ephyrae $2 \mathrm{~mm}$ in diameter) are produced in shallow water by benthic polyps in early spring as water temperatures increase (at approximately $\left.17^{\circ} \mathrm{C}\right)($ Cargo \& Schultz 1966, 1967). By mid to late summer, medusae typically are abundant in the mesohaline Chesapeake Bay. Medusa numbers decline in late summer and autumn, and they are absent from the bay waters in winter. The benthic polyp stage survives the winter as a dormant cyst.

The environmental conditions associated with Chrysaora quinquecirrha production and the presence of the medusa in Chesapeake Bay are well established. Upper lethal temperature of medusae (Gatz et al. 1973) and polyps (Cargo \& Schultz 1967) is $34^{\circ} \mathrm{C}$. However, lower lethal temperatures for medusae and polyps differ. Medusae do not survive below $10^{\circ} \mathrm{C}$, whereas polyps usually encyst when temperatures reach $3^{\circ} \mathrm{C}$ or below. Purcell et al. (1999) found that ephyra and polyp production of benthic $C$. quinquecirrha polyps were highest at intermediate salinities of 10 to 25 (tested 5 to 35$)$. Cool temperatures $\left(15\right.$ and $\left.20^{\circ} \mathrm{C}\right)$ delayed strobilation. When prey were more abundant, production of ephyrae, but not polyps, increased.

Population size and distribution of the medusae in Chesapeake Bay show dramatic interannual variations that are correlated with hydrographic and environmental factors (Cargo \& King 1990, Purcell et al. 1999, Purcell \& Decker 2005). Cargo \& King (1990) showed that streamflow for the entire Chesapeake system during January-June explained nearly two-thirds of the variation in mid-summer medusa counts at one location (Solomons, Maryland) in the mesohaline bay. Late spring salinities and temperatures also influenced summer medusa abundance (Cargo \& King 1990), presumably because these factors directly affect strobilation. This was illustrated by a bay-wide study that showed that medusa numbers were 2 orders of magnitude lower in July 1996, when water temperatures, salinities, and zooplankton densities all were lower compared with July 1995 (Purcell et al. 1999).

In the present study, we developed and validated bay-wide habitat models to predict medusa occurrence and their concentration in surface waters throughout the Chesapeake Bay. We also show example calculations where the occurrence model was forced using the output from a 3-dimensional hydrodynamic model. This allowed us to generate bay-wide synoptic near-real time predictions (i.e. 'nowcasts', Brown et al. 2002) of the probability of Chrysaora quinquecirrha medusa presence, which were compared with ob- 
served distributions. This nowcasting model is being employed to provide near-real time occurrence probabilities of medusae throughout the bay and tributaries (see http://coastwatch.noaa. gov/seanettles).

\section{MATERIALS AND METHODS}

Development of jellyfish habitat models. Because salinity and temperature have such dramatic effects on the production of Chrysaora quinquecirrha medusae, we were able to develop models that employ these predictor variables to define their habitat (Brown et al. 2002). Specifically, we developed 2 habitat models, one that predicts the likelihood of medusae occurring and another that predicts potential concentration. These empirical models use data collected from 1064 stations in the Chesapeake Bay and its tributaries during the spring, summer and fall of 1987-2000 (Fig. 1). Medusae were collected with a $1 \mathrm{~m}$ diameter, $0.8 \mathrm{~mm}$ mesh plankton net and a $1 \mathrm{~m}^{2}, 280 \mu \mathrm{m}$ mesh Tucker trawl with attached flowmeters within the surface waters ( 0 to $10 \mathrm{~m}$ ) of the mainstem Chesapeake Bay and selected tributaries (Patuxent River, Broad Creek, Tred Avon River). Surface temperature and salinity were recorded at each trawl station.

We randomly separated our medusa presence/absence dataset into 2 portions. Two-thirds of the data $(\mathrm{n}=709)$ was selected for model construction or fitting (the 'training' dataset) and the remaining third ( $\mathrm{n}=355)$ was used for validation (the 'test' dataset). We repeated the process for the medusa density dataset.

Likelihood of occurrence model. Relationships among Chrysaora quinquecirrha medusa presence, temperature and salinity were analyzed with logistic regression in order to estimate the likelihood of medusa occurrence. Logistic regression applies maximum likelihood estimation after transforming the dependent variable (medusa presence, medusa absence) into a Logit variable, where the Logit is the natural $\log$ of the odds of medusae occurring (Hosmer \& Lemeshow 2000). Logistic regression is an appropriate model to use because it regresses a binary dependent variable (presence/absence) against continuous or categorical independent variables, has relaxed assump-

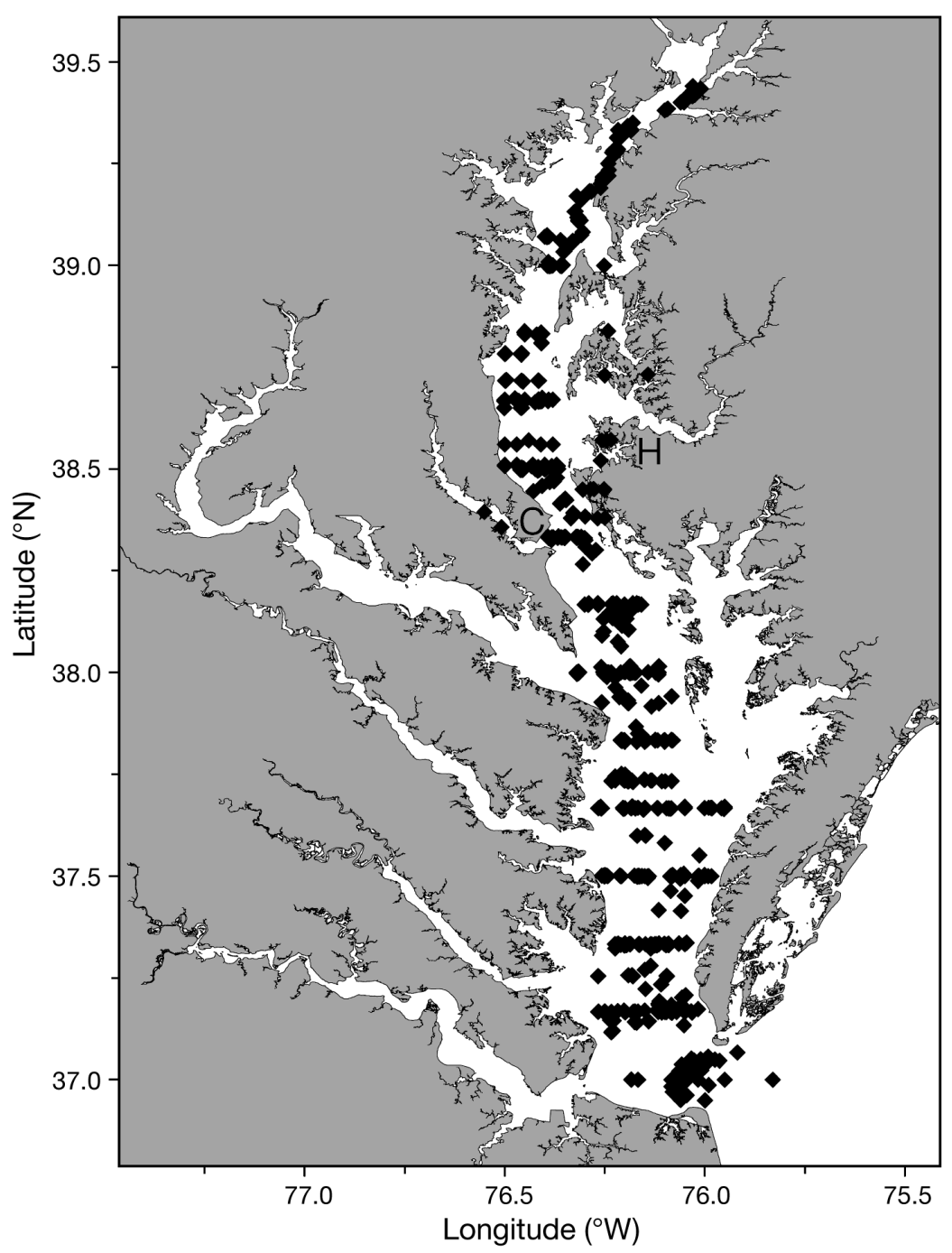

Fig. 1. Chrysaora quinquecirrha. Sampling locations for medusae, sea-surface temperature and salinity observations $(\mathrm{n}=1064)$ in the Chesapeake Bay and selected tributaries $(\diamond)$, at the Chesapeake Biological Laboratory (C) and Horn Point Laboratory $(\mathrm{H})$ piers

tions of normality of independent variables (Hosmer \& Lemeshow 2000), and has been used to develop predictive models within geographical information systems (GIS) to map potential habitat of coastal and terrestrial organisms (e.g. Kelly et al. 2001, Odom et al. 2001).

In the logistic regression results presented, the significance of each predictor variable was tested through the calculation of a likelihood ratio (LR) test statistic, which compared the explanatory power of the model with and without the parameter in question. In the univariate case, the model was compared to a 'null' (intercept-only) model. In this way, we used LR test statistics to find the best fit model. The LR statistic is distributed chi-square with $i$ degrees of freedom, where $i$ is the number of independent variables (Agresti 1990). 
STATISTICA (version 7, StatSoft) was used to conduct logistic regressions.

Concentration model. Relationships among Chrysaora quinquecirrha medusa concentration (no. $\mathrm{m}^{-3}$ ), temperature and salinity were developed by another empirical method we called 'binning'. The medusa concentration training dataset was binned according to temperature and salinity, at intervals of 2 degrees Celsius and 1 unit of salinity $(\mathrm{n}=198)$. The 50th, 75th, 95th, and 100th percentiles of medusa concentration were then calculated for each temperature and salinity bin. The geostatistical Kriging method was used to create a surface for each percentile dataset at a fine grid density. Gridded values interpolated from each surface were output to a data file. By using these data files as look-up tables, potential medusa concentration can be predicted from any given combination of temperature and salinity. Look-up tables created from the 50th, 75th, 95th, and 100th percentiles of medusa concentration and modeled salinity and temperature data (described below) allowed us to make predictions of the likelihood of medusae occurring in low, moderate, high and very high concentrations.

Model validation. In order to assess the predictive performance of our empirically derived habitat models, we tested the Chrysaora quinquecirrha medusa occurrence and concentration models against independent medusa and environmental data. To validate the occurrence model, the physical measurements of the test dataset $(n=354)$, i.e. the subset of temperature and salinity data not used to build the model, were input into the logistic function derived to predict the likelihood of medusa occurrence. Model predictions were evaluated by comparison of these resulting modelderived occurrences with observed medusa occurrences in the test dataset. We examined reliability and validity of the occurrence model by calculating percent agreement and Cohen's $\kappa$ (Cohen 1960). In order to use these measures of agreement, predicted occurrence probabilities were converted to a dichotomous variable (presence/absence), where medusae were scored as 'absent' if modeled probabilities were $<0.5$. These agreement analyses were repeated after occurrences were scored as 'absent' if their predicted probabilities were set at a more conservative level of $<0.1$.

We used an additional data source, medusa sight counts, to assess the skill of the occurrence model in predicting the presence of Chrysaora quinquecirrha medusae. Daily medusa counts were made by walking the length of the Horn Point and Chesapeake Biological Laboratory (HPL and CBL $38^{\circ} 35.90^{\prime} \mathrm{N}$, $76^{\circ} 08.40^{\prime} \mathrm{W}$, and $38^{\circ} 19^{\prime} \mathrm{N}, 76^{\circ} 27.16^{\prime} \mathrm{W}$, respectively; Fig. 1) piers from May 1 to October 31, 2002 . Seasurface-temperature and salinity data from these locations were also collected for this period. These physical measurements were input into the logistic function for predicting the likelihood of medusa occurrence in order to eliminate the error in the medusa predictions due to inaccuracy of the temperature and salinity estimates provided by the hydrodynamic model (see next section). We compared average weekly medusa counts to the likelihood of medusa occurrence hindcasted for the same period and location. Relationships between the observed counts and the predicted occurrence at these sites were analyzed in order to assess the reliability of our C. quinquecirrha predictions throughout the course of the jellyfish season.

To assess the concentration model, predicted values of the 95th percentile of medusa concentration (i.e. the gridded values interpolated from the 'binned' training dataset) were compared with the 95th percentile of observed medusa concentrations (i.e. the 'binned' test dataset) at corresponding temperature and salinity values $(\mathrm{n}=156)$. The relationship between predicted and observed concentration was examined by crosscorrelation analysis.

We conducted statistical analyses with STATISTICA 7.0. Prior to running tests, we examined whether the data violated the basic assumptions of normal distribution and constant variance. If assumptions were violated, then non-parametric alternatives were used.

Prediction of jellyfish distributions. Models are currently being used to generate bay-wide maps that illustrate the likelihood of Chrysaora quinquecirrha medusa occurrence in Chesapeake Bay. These predictions are generated by applying estimates of ambient temperature and salinity, which are simulated by a physical model Curvilinear Hydrodynamics in 3Dimensions (CH3D), to the medusa occurrence habitat model (Fig. 2).

CH3D was originally developed by Sheng (1987) and later extensively modified at the US Army Corps of Engineers Waterways Experiment Station for the Chesapeake Bay (Wang \& Johnson 2000). It is a curvilinear, finite difference z-coordinate model and is currently used, in combination with a water quality model, by the US Environmental Protection Agency (EPA) Chesapeake Bay Program to study the potential benefits of proposed nutrient-loading reductions. Our version of CH3D is modified to run using near-real time forcing, such as river outflow and air temperature, and is unique in that it allows us to simulate contemporary salinity and temperatures in the bay.

By coupling estimates of temperature and salinity predicted by CH3D with the medusa habitat model, retrospective predictions (i.e. 'hindcasts') and nowcasts of medusa occurrence can be generated on a weekly basis for the period 1996 to present (Fig. 2). Selected hindcasts are presented in this paper and the most current nowcast is staged on the World Wide 


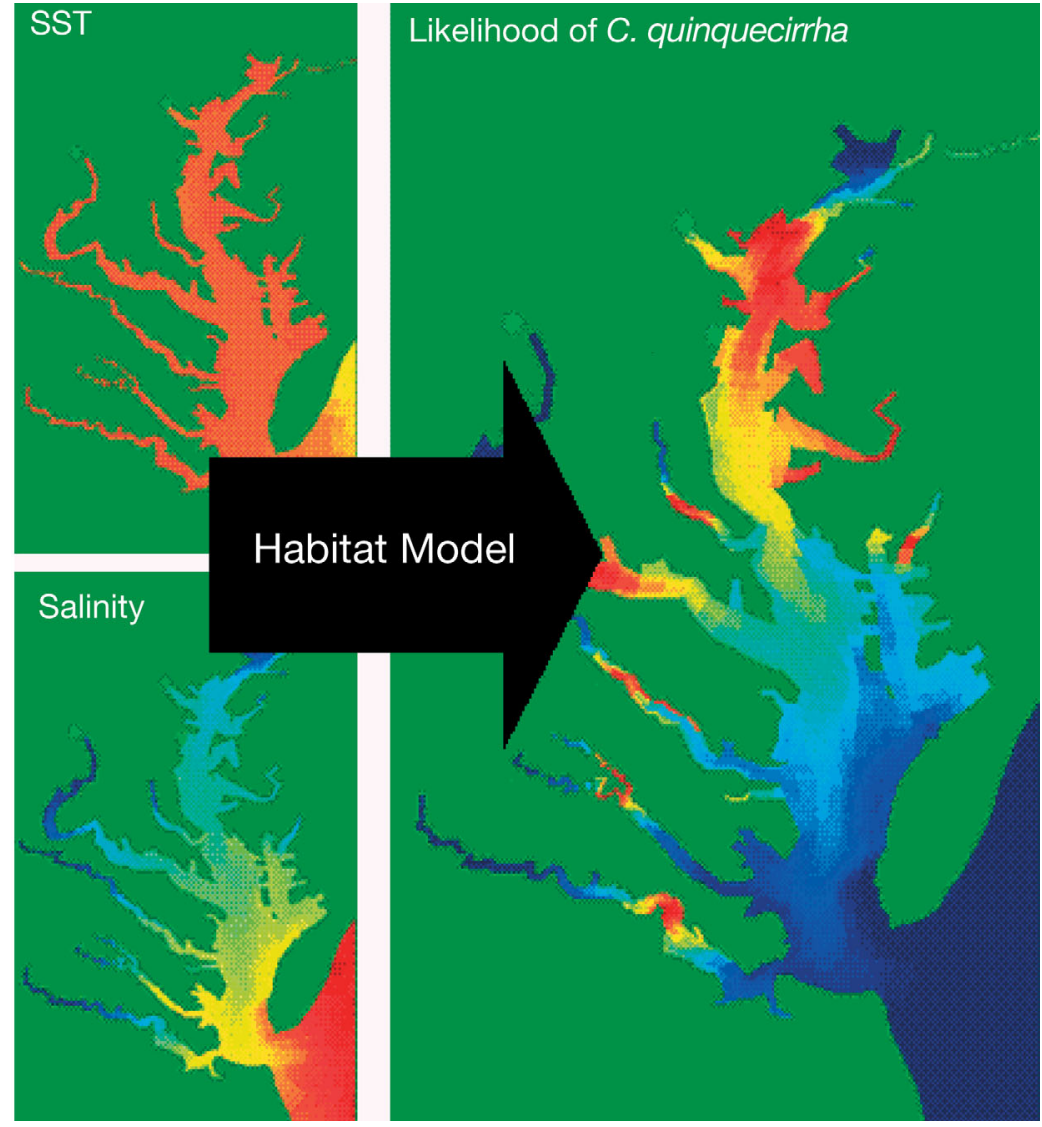

Fig. 2. Chrysaora quinquecirrha. Example maps generated by using near-real time or historical temperature and salinity fields in the habitat model to predict the distribution and likelihood of medusa occurrence in Chesapeake Bay. SST: seasurface temperature

Web (http://coastwatch.noaa.gov/seanettles). A full description of this system will be presented elsewhere by Brown et al. (unpubl.).

\section{RESULTS}

\section{Jellyfish likelihood of occurrence model}

Concentrations of Chrysaora quinquecirrha medusae were found within narrow ranges of temperature and salinity (Fig. 3). Medusa concentrations were highest at the upper end of the temperature range $\left(25\right.$ to $\left.31^{\circ} \mathrm{C}\right)$ and at intermediate salinities (10 to 16). Therefore, it was necessary to transform the salinity data to fit the linear assumption of the logistic regression model. To do so, we defined the 'optimal' salinity to be that in which medusae are most likely to be found (i.e. 13.5) and then calculated a difference from this optimum for each salinity measurement. Small differences from the optimum were associated with a relatively high likelihood of medusa occurrence, and this likelihood declined as the difference between the optimal and actual salinity increased.

We found a tight relationship between Chrysaora quinquecirrha medusa presence and both temperature and salinity (Fig. 4). The following equations predicted the probability of occurrence as a function of temperature and difference from optimal salinity (salinity opt $)$, respectively: Logit $=-10.189+(0.373 \times$ temperature), and Logit $=0.292-\left(0.555 \times\right.$ salinity $\left._{\text {opt }}\right)$, where Logit, estimated by logistic regression, is the

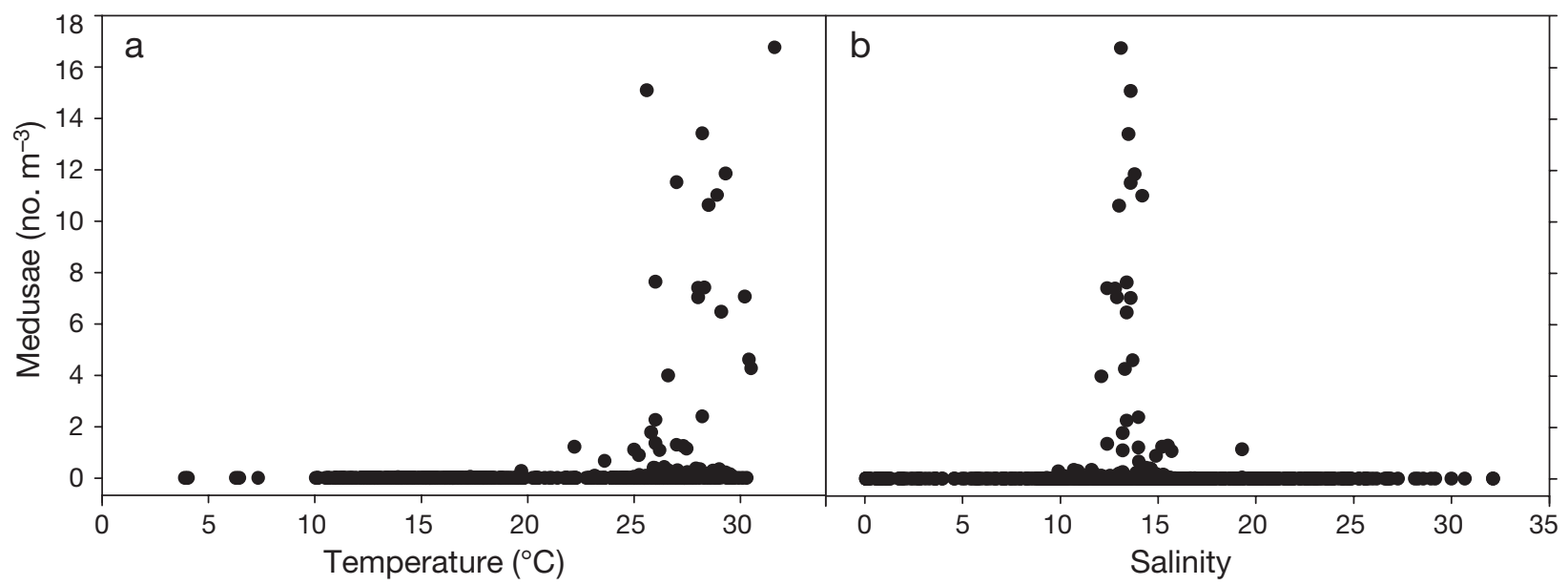

Fig. 3. Chrysaora quinquecirrha. Empirical data illustrating the relationships between medusa concentration and (a) sea-surface temperature and (b) sea-surface salinity. These data $(\mathrm{n}=710)$ were used to construct the medusa occurrence model with logistic regression and the density model by binning medusa concentrations at intervals of temperature and salinity 


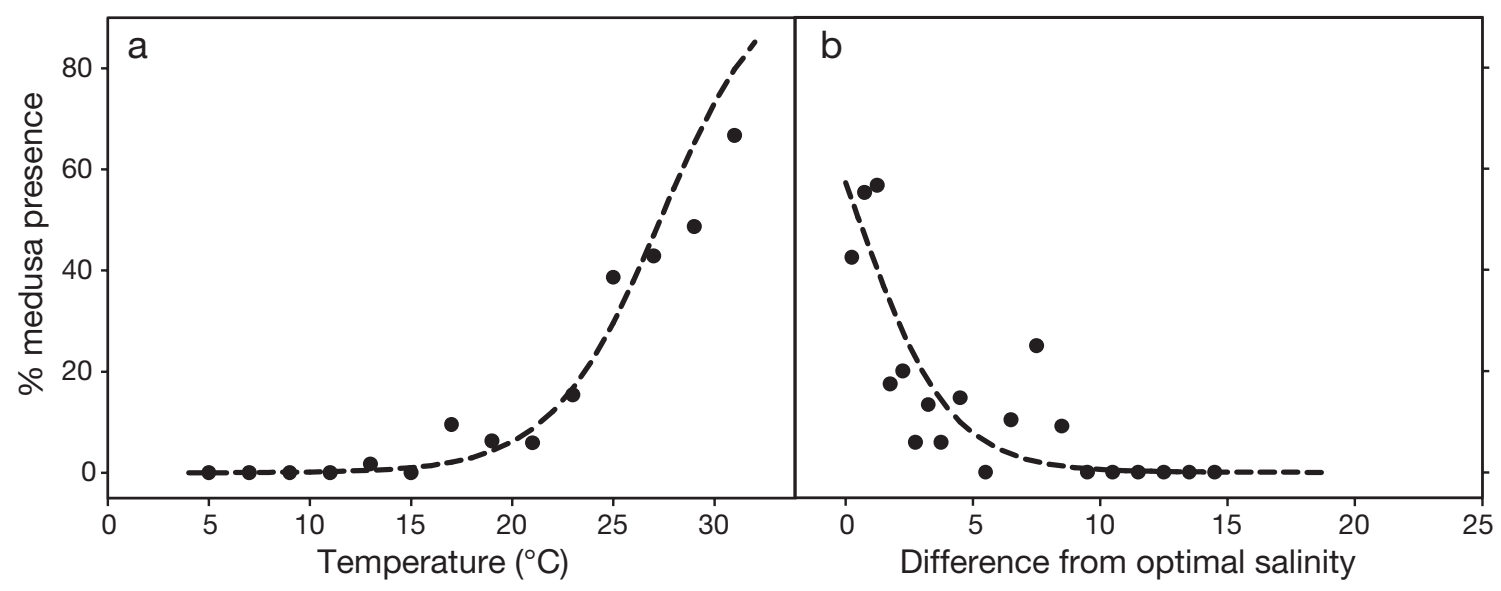

Fig. 4. Chrysaora quinquecirrha. Relationships between (a) the probability of medusa occurrence and sea-surface temperature and (b) the difference from optimal salinity. Both temperature and salinity were good predictors of medusa presence. Trend lines were determined by logistic regression analysis

natural log of the odds of medusae occurring. S-shaped probability curves were fit to both temperature and salinity data by transforming each linear regression

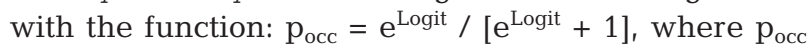
was the probability of medusa occurrence (Fig. 4). Type 1 LR tests comparing each model to its 'null' model, indicated that temperature and salinity each had significant effects on the observed likelihood of medusa occurrence (LR test statistic $=241.5, \mathrm{df}=1, \mathrm{p}<0.001$ and LR test statistic $=176.3, \mathrm{df}=1, \mathrm{p}<0.001$, respectively, Table 1).

In order to develop a jellyfish occurrence model that used both temperature and salinity, we analyzed the relationships among these variables using a multiple logistic regression model. A Type 1 LR test with 2 degrees of freedom comparing the full model including temperature and salinity to a reduced model with neither of the factors indicated that temperature and salinity had a significant effect on the observed frequency of Chrysaora quinquecirrha medusa occurrence (LR test statistic $=353.8, p<0.001$, Table 2 ). Our results indicated that the probability of medusa occurrence was predicted as a function of temperature and salinity: Logit $=-8.120+(0.351 \times$ temperature $)$ - $\left(0.572 \times\right.$ salinity $\left._{\text {opt }}\right)$. The HosmerLemeshow goodness-of-fit test $=7.417$, and was insignificant $(p>0.05)$, suggesting that the model was fit to the data well. In addition, the multiple logistic regression including both tem- perature and salinity provided a better fit to the data than the reduced, univariate equations containing either temperature (LR test statistic $=112.3, \mathrm{df}=2, \mathrm{p}<$ $0.001)$ or salinity (LR test statistic $=177.5, \mathrm{df}=2, \mathrm{p}<$ $0.001)$.

Table 1. Chrysaora quinquecirrha. Results of univariate logistic regression analysis of medusa occurrence in Chesapeake Bay $(n=709)$. Salinity ${ }_{\text {opt }}$ : optimal salinity. The Wald statistic tests the significance of individuals predictors; Hosmer-Lemeshow: goodness-of-fit statistic. Bold: $p \leq 0.05$

\begin{tabular}{|c|c|c|c|c|c|}
\hline & & & Test statistic & df & $\mathrm{p}$ \\
\hline Individual predictor & Coefficients & SE & Wald & & \\
\hline Constant & -10.189 & 0.989 & 106.047 & 1 & $<0.001$ \\
\hline Temperature & 0.373 & 0.0379 & 96.754 & 1 & $<0.001$ \\
\hline Constant & 0.292 & 0.154 & 3.597 & & 0.058 \\
\hline Salinity ${ }_{\text {opt }}$ & 0.555 & 0.064 & 76.243 & & $<0.001$ \\
\hline \multicolumn{6}{|c|}{ Overall model evaluation } \\
\hline \multirow[t]{2}{*}{ Temperature } & \multirow{2}{*}{\multicolumn{2}{|c|}{$\begin{array}{l}\text { Likelihood ratio test } \\
\text { Hosmer-Lemeshow test }\end{array}$}} & 241.511 & 1 & $<0.001$ \\
\hline & & & 15.502 & 8 & 0.050 \\
\hline \multirow{2}{*}{ Salinity $_{\text {opt }}$} & \multirow{2}{*}{\multicolumn{2}{|c|}{$\begin{array}{l}\text { Likelihood ratio test } \\
\text { Hosmer-Lemeshow test }\end{array}$}} & 176.300 & 1 & $<0.001$ \\
\hline & & & 6.297 & 8 & 0.614 \\
\hline
\end{tabular}

Table 2. Chrysaora quinquecirrha. Results of multivariate logistic regression analysis of medusa occurrence in Chesapeake Bay $(n=709)$. Salinity opt: optimal salinity. The Wald statistic tests the significance of individuals predictors; Hosmer-Lemeshow: goodness-of-fit statistic. Bold: $\mathrm{p} \leq 0.05$

\begin{tabular}{|lcccccc|}
\hline & & & Test statistic & df & $\mathrm{p}$ \\
\hline Individual predictor & Coefficients & SE & Wald & & \\
Constant & -8.120 & 1.050 & 59.835 & 1 & $<\mathbf{0 . 0 0 1}$ \\
Temperature & 0.351 & 0.041 & 73.988 & 1 & $<\mathbf{0 . 0 0 1}$ \\
Salinityopt & -0.572 & 0.075 & 58.132 & 1 & $<\mathbf{0 . 0 0 1}$ \\
& & & & & \\
Overall model evaluation & & & 353.831 & 2 & $<\mathbf{0 . 0 0 1}$ \\
Likelihood ratio test & & & 7.415 & 8 & 0.493 \\
Hosmer-Lemeshow & & & & & \\
\hline
\end{tabular}




\section{Jellyfish concentration model}

By binning Chrysaora quinquecirrha medusa concentrations (no. $\mathrm{m}^{-3}$ ) at intervals of $2^{\circ} \mathrm{C}$ and 1 unit of salinity, we determined that the highest concentrations of medusae were observed in narrow ranges of temperature and salinity. This pattern was observed in each percentile range (i.e. 50th, 75th, 95th, 100th); however, we present here the 95th percentile surface because it represents the near-upper boundary of potential medusa concentration. This technique illustrated that the predicted distribution of medusa concentration was extremely well defined in the temperature-salinity space and reflected the relatively narrow habitat in which medusae occurred in the bay.

\section{Habitat model validation}

We analyzed relationships between observed and predicted medusa presence in order to assess the reliability of our predictions. Model-predicted probability of medusa occurrence corresponded well with observed medusa occurrence in the test dataset (Fig. 5). Median predicted medusa probability of occurrence was significantly higher where medusae were observed (Mann-Whitney Rank Sum Test; $T=$ $21495.5, \mathrm{p}<0.001)$. Overall, $86.7 \%$ of the estimates were correctly predicted by the model (Table 3 ) and Cohen's $\kappa=0.62$ indicated 'substantial' (Landis \& Koch 1977) agreement between model-predicted probabilities (where 'absent' $<0.5$ ) and observed medusa occurrences. The proportion of observations misclassified by the model, specifically, the false positive and false negative rates, were 32.5 and $7.7 \%$, respectively (Table 3 ). We expect the occurrence of false positive model predictions to be higher than false negative predictions due to the patchy distribution of medusae and the possibility of sampling artifacts (i.e. under-sampling by the net when medusae occur at low concentrations). The agreement fluctuated as we varied the level selected for scoring a probability estimate as 'absent'. Setting the 'absent' level to 0.1 increased the false positive rate to $50 \%$ and decreased the false negative rate slightly to $4.5 \%$ (Table 3 ). Use of this more conservative scoring level provided a Cohen's $\kappa=0.5$, indicating a 'moderate' (Landis \& Koch 1977) agreement between model-predicted probabilities and observed medusa occurrences.

Model-predicted potential concentrations of medusae also corresponded well with the observed values of the test dataset (Figs. 6 \& 7). The model explained $51 \%$ of the variance in medusa concentration. We found a significant association between the highest potential concentration of medusae predicted by the

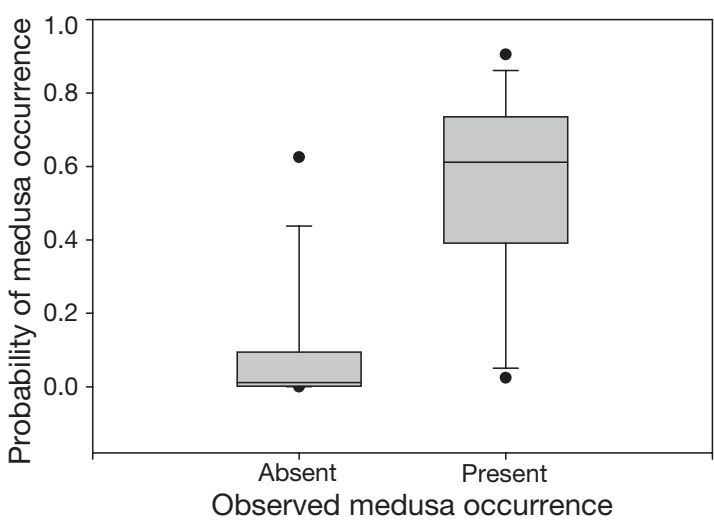

Fig. 5. Chrysaora quinquecirrha. Evaluation of medusa occurrence model performance using observations not used in model-fitting, i.e. the test dataset $(\mathrm{n}=354)$. Modeled probabilities of medusa occurrence were compared with observed medusa occurrence (i.e. absent, present). Boxes represent 25th and 75 th percentiles; horizontal lines indicate the medians of each group; bars represent 5th and 95th percentiles; dots indicate probabilities outside the 5 th to 95 th percentile range

'binning method' and those observed at corresponding temperature and salinity values (Spearman rank correlation $\left.\mathrm{r}_{\mathrm{S}}=0.48, \mathrm{p}<0.05, \mathrm{n}=156\right)$. Predicted concentrations deviated most from in situ concentrations where observed medusa densities were near zero (Fig. 7), and resulted from the smoothing method used to create a predictive surface from the percentile dataset and from the patchy distribution of observed medusae.

A 6 mo time series at 2 locations in Chesapeake Bay showed the relationships among temperature, salinity and medusae throughout the season, and also the level of agreement between these observed and predicted measures (Fig. 8). When the occurrence model was forced with weekly observed sea-surface temperature and salinity, occurrence likelihoods were similar to those predicted from modeled temperature and sal-

Table 3. Chrysaora quinquecirrha. Observed and predicted frequencies for medusa occurrence (no. of sites) in Chesapeake Bay. Predicted medusa occurrences were estimated by logistic regression, and scored as 'absent' if modeled probability of occurrence ( $\mathrm{p}_{\text {occ }}$ ) was $<0.5$ or $<0.1$

\begin{tabular}{|lcccc|}
\hline & Present & Absent & Total & \% false \\
\hline Observation & 75 & 279 & 354 & \\
Prediction & & & & \\
(absent if $\left.\mathrm{p}_{\text {occ }}<0.5\right)$ & & & & \\
Present & 54 & 26 & 80 & 32.5 \\
Absent & 21 & 253 & 274 & 7.7 \\
\% correct & 72.0 & 90.7 & 86.7 & \\
Predicted & & & & \\
(absent if $\left.\mathrm{p}_{\text {occ }}<0.1\right)$ & & & & \\
Present & 65 & 65 & 130 & 50 \\
Absent & 10 & 214 & 224 & 4.5 \\
$\%$ correct & 86.7 & 76.7 & 78.8 & \\
\hline
\end{tabular}




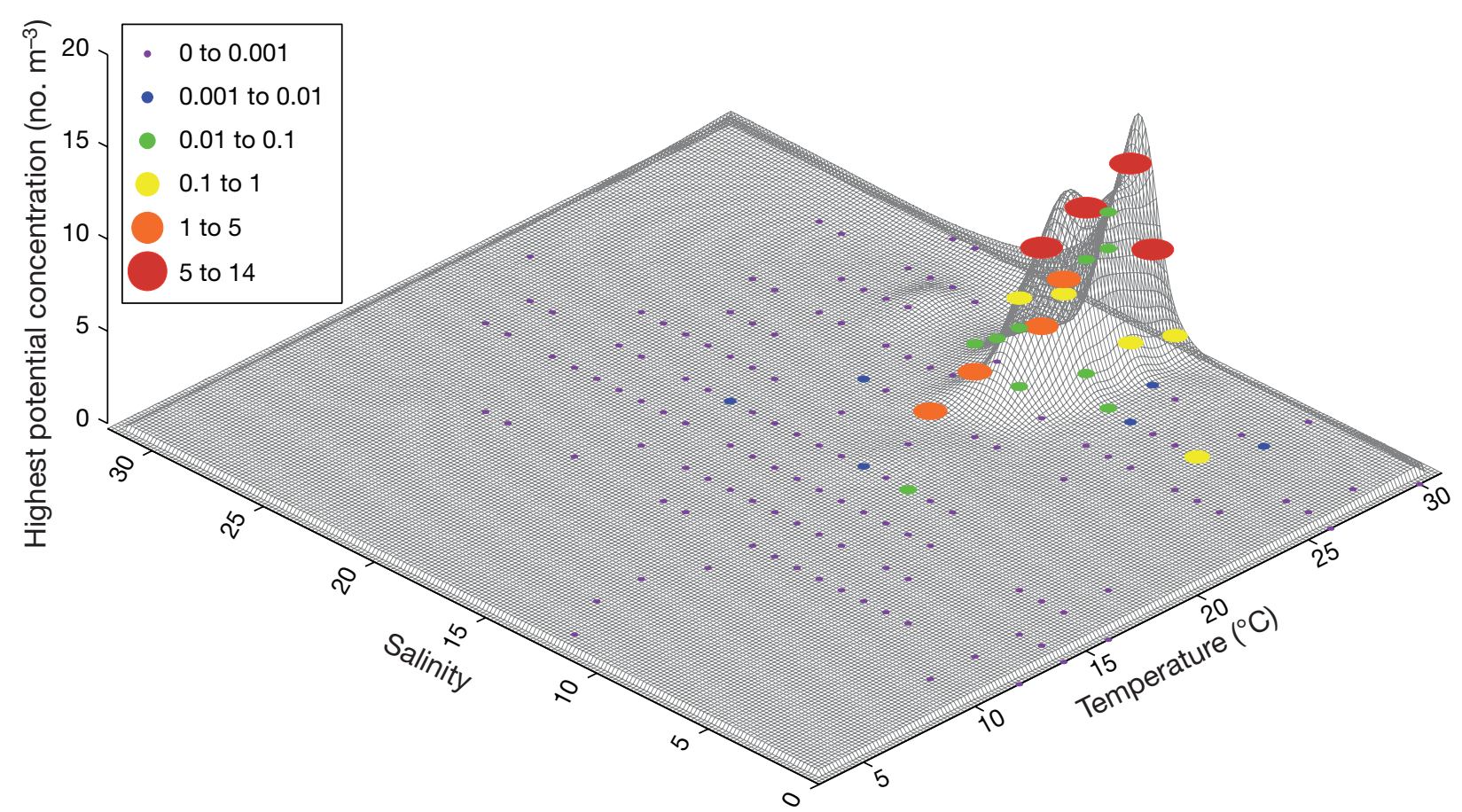

Fig. 6. Chrysaora quinquecirrha. The highest potential medusa concentration (i.e. the 95th percentile of medusa density) in surface waters of Chesapeake Bay over ranges of ambient sea-surface salinity and temperature. Surface plot illustrates estimates of the 95th percentile of medusa density interpolated from the 'training dataset' $(\mathrm{n}=710)$; circles indicate the observed 95th percentile of medusa density from the 'test dataset' $(n=156)$. Maximum medusa densities in the training and test datasets were 16.8 and $13.1 \mathrm{~m}^{-3}$, respectively

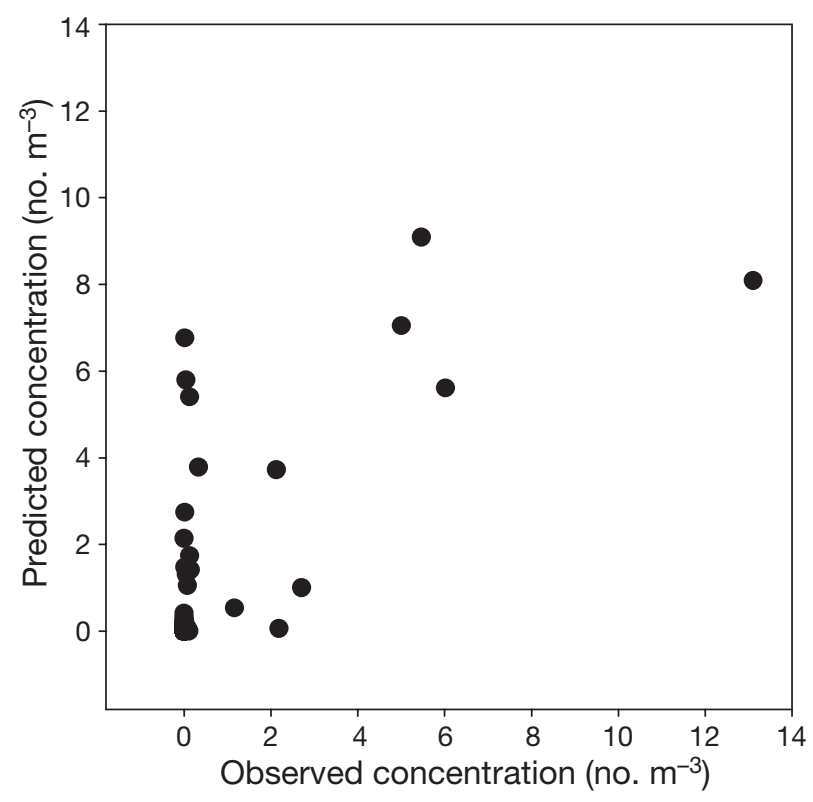

Fig. 7. Chrysaora quinquecirrha. Relationship between highest potential concentration of medusae (no. $\mathrm{m}^{-3}$ ) predicted by the 'binning method' and the 95th percentile of medusa concentrations (no. $\mathrm{m}^{-3}$ ) observed at independent sampling locations in Chesapeake Bay. Data points $(n=156)$ indicate medusa concentrations at corresponding temperature and salinity values inity (Fig. 8a,b). We found significant, linear relationships between the observed medusa number and predicted occurrence at both the HPL and CBL piers during this period of late spring through early fall (Fig. 9, Table 4); however, observed medusa concentrations at both locations increased later and declined earlier than the model predicted (Fig. 8). Similarly, statistically significant associations were found between in situ measures of temperature and salinity and those predicted by the hydrodynamic model CH3D. In all cases, modelpredicted values explained a significant portion of variance in observed measures of medusae, temperature and salinity (Table 4); however, comparisons of observed and predicted temperature and, in particular, salinity diverge from the expected 1:1 relationships. At least some of the infidelities in the physical model (and hence the medusa predictions) may be related to the close proximity of these sampling sites to the shore. CH3D contains few grid cells across the tributaries where the piers are located, and thus will not accurately represent local vagaries in temperature and salinity (i.e. the model will tend to average these values over a large area).

Examination of weekly hindcasted predictions and observations in 2002 revealed the relative influence of temperature and salinity on the temporal variability of 


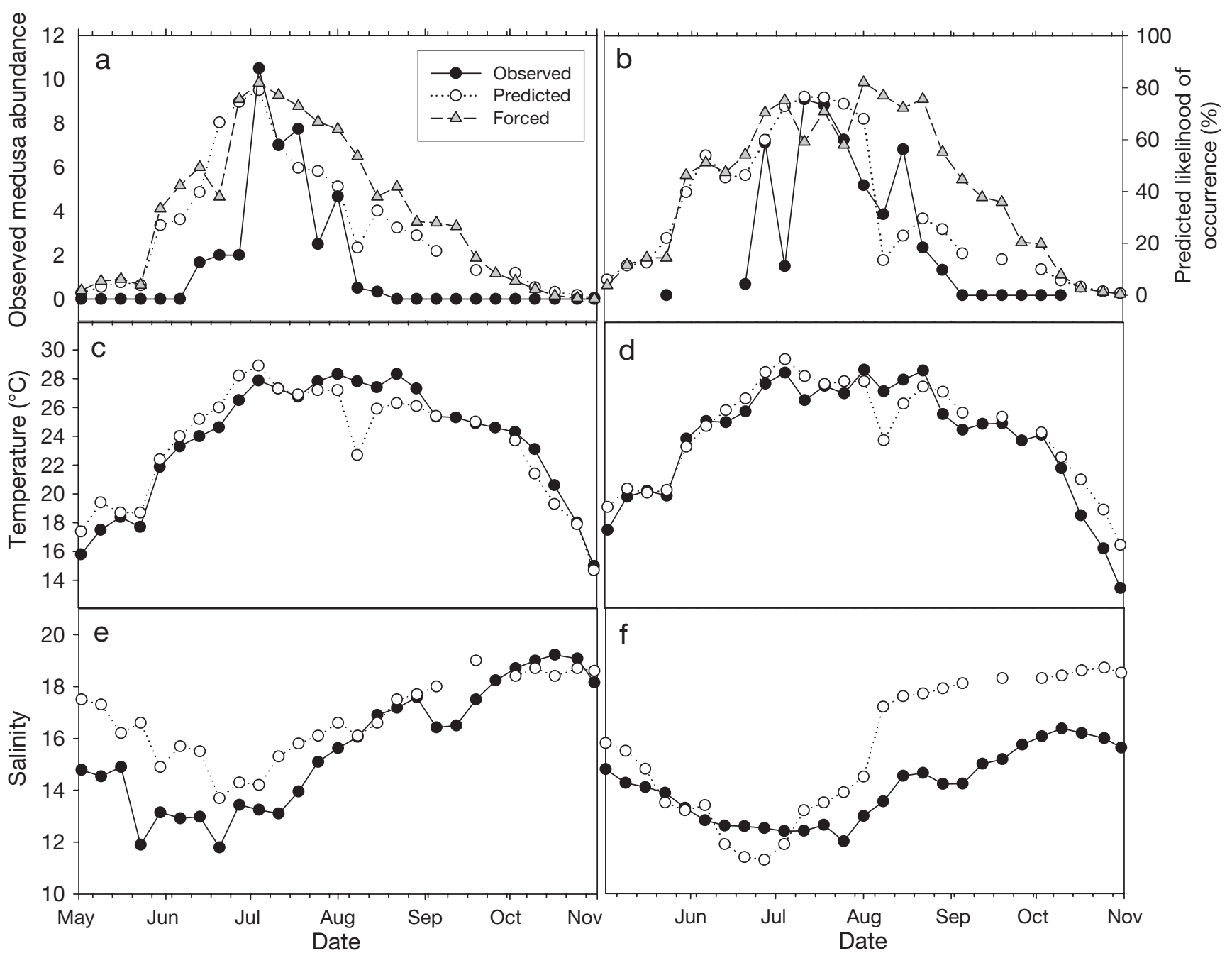

Fig. 8. Chrysaora quinquecirrha. Weekly observed (๑) and model-predicted (O) measures of $(\mathrm{a}, \mathrm{b})$ medusae, (c,d) sea-surface temperature, and $(\mathrm{e}, \mathrm{f})$ salinity at the Chesapeake Biological Laboratory $(\mathrm{a}, \mathrm{c}, \mathrm{e})$ and Horn Point Laboratory $(\mathrm{b}, \mathrm{d}, \mathrm{f})$ piers during the period May 1-October 31, 2002. Results of forcing the occurrence model with weekly observed sea-surface temperature and salinity shown in (a) and (b) $(\triangle)$

Chrysaora quinquecirrha medusae in Chesapeake Bay. From May 1 through June 20, medusae were absent or rare at 2 sampling locations in the mesohaline bay (Fig. 8a,b); during this period, salinity, but not temperature (Fig. 8c-f), was within what we have defined as 'optimal' for C. quinquecirrha (i.e. 10 to 16 salinity, 25 to $31^{\circ} \mathrm{C}$ ). From June 27 through August 1, medusae were present at these locations when both salinity and temperature were within 'optimal' ranges. After August 1, medusae were predicted to occur in the upper reaches of the bay and tributaries, and observations revealed that they were not present at either mid-bay site (Fig. 8a,b); during August 2002, salinity was predicted and observed to be greater than or at the upper end of the 'optimal' range for the medusae, whereas temperature was still within their preferred range (Fig. 8e-f). These observations suggest that temperature may induce the $C$. quinquecirrha medusa bloom at the beginning of the season, but that changes in salinity may be responsible for the decline of medusa populations near the end of the season.

\section{Predictions of jellyfish distributions}

Maps generated by applying the habitat model to historical temperature and salinity fields predicted the distribution and likelihood of Chrysaora quinquecirrha medusa occurrence in Chesapeake Bay (Figs. 2 \& $10 a, b)$. These predicted distributions of medusa occurrence are realistic because they correspond well with in situ medusa observations (Fig. 10c,d). Our mapping procedure illustrated the dramatic effect of freshwater 

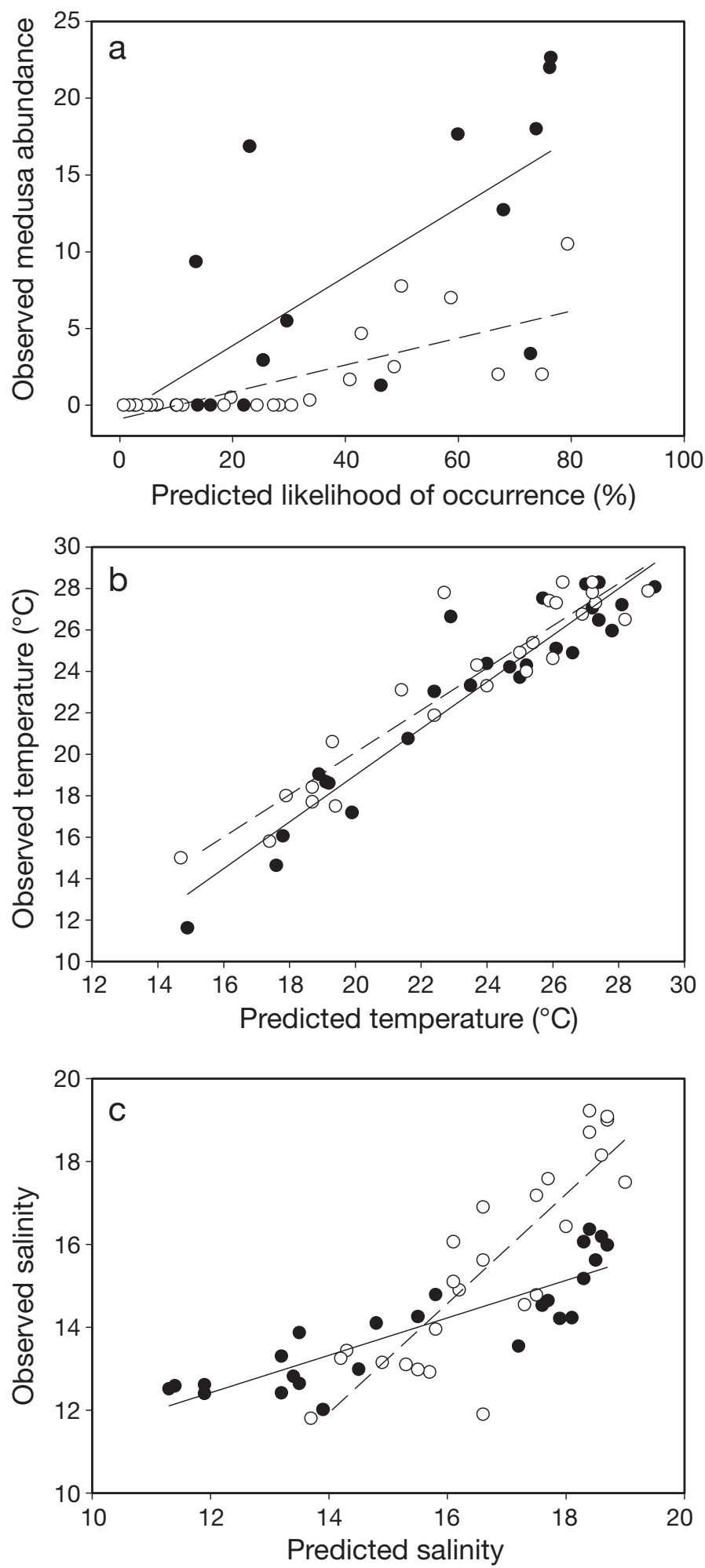

Fig. 9. Chrysaora quinquecirrha. Relationships between observed and model-predicted (a) medusae, (b) sea-surface temperature and (c) salinity at the Horn Point Laboratory (HPL, $\bullet$, solid lines) and Chesapeake Biological Laboratory ( $\mathrm{CBL}, \mathrm{O}$, dashed lines) piers during the period May 1 to Ocobert 31, 2002. Lines were determined by linear regression. Regression results are presented in Table 4 input into Chesapeake Bay on inter-annual medusa spatial patterns. Freshwater flow was extremely high in 1996, and resulted in reduced salinities (Fig. 11a) and medusae occurring only in the southern portion of the bay as predicted by our model (Fig. 10a,c). By contrast, 1999 had relatively low freshwater flow, which resulted in high salinities in the middle bay (Fig. 11b) and medusae were predicted and observed to occur in the upper bay (Fig. 10b,d). In 1999, medusae were also present at 2 southern locations where the model predicted low probability of occurrence (Fig. 10b,d); however, these observations were the result of only 1 individual collected at each location. Surface water temperature in the bay tended to be uniformly warm from north to south during late June through August (Fig. 11c,d), and thus would not significantly affect medusa occurrence and distribution (Fig. 10). By contrast, salinity had a strong north-south gradient in the bay in summer and had a dramatic effect on where medusae occurred in the bay. Medusae were predicted and observed to occur in waters where surface salinity ranged from 10 to 16 (Figs. 10 \& 11a,b). In addition to interannual fluctuations due to changes in hydrography, flow and resultant salinity influenced the distribution and occurrence of $C$. quinquecirrha within the medusa season as well (Fig. 8).

\section{DISCUSSION}

Our models illustrated that the habitat of Chrysaora quinquecirrha medusae in Chesapeake Bay has a narrowly defined combination of temperature and salinity. This 'preference' for specific thermal and saline conditions determined the temporal and spatial patterns of medusae in the bay and its tributaries. These patterns changed as fluctuating climatic conditions altered the temperature and salinity of this estuarine system. Generally, medusae first appear in May or June in the tributaries of the mesohaline (i.e. salinity range 5 to 18 ) region, and are seen a month later in the mainstem bay (Purcell 1992, Purcell et al. 1994b). The highest medusa concentrations (up to $16 \mathrm{~m}^{-3}$ ) occur in the tributaries in July and August (Purcell 1992). Populations decline through the fall and only a few medusae are observed in October (Purcell et al. 1994b). Predictions generated by our models and associated nowcasting system agreed well with these previous observations of the temporal and spatial dynamics of C. quinquecirrha medusae in Chesapeake Bay.

We hypothesize that the habitat preference and resulting temporal and spatial distributions of Chrysaora quinquecirrha medusae are determined by factors affecting the abundance of polyps, the production of ephyrae, and the survival and movement of me- 
Table 4. Chrysaora quinquecirrha. Results of linear regression comparing observed and model-predicted measures of medusae, sea-surface temperature (SST), and sea-surface salinity at Horn Point Laboratory (HPL) and Chesapeake Biological Laboratory (CBL) piers. In each comparison, the dependent variable contains observed values and the independent variable contains the predicted values; $\beta$ : linear regression coefficient; $\alpha$ : linear regression intercept. Bold: $p \leq 0.05$

\begin{tabular}{|c|c|c|c|c|c|c|c|c|c|}
\hline \multirow{2}{*}{$\begin{array}{l}\text { Dependent variable } \\
\text { (observed) }\end{array}$} & \multirow{2}{*}{$\begin{array}{l}\text { Independent variable } \\
\text { (model-predicted) }\end{array}$} & \multirow{2}{*}{$\mathrm{df}$} & \multicolumn{3}{|c|}{ - Coefficient } & \multicolumn{3}{|c|}{ - Intercept } & \multirow{2}{*}{$\mathrm{R}^{2}$} \\
\hline & & & $\beta$ & & $\mathrm{p}$ & $\alpha$ & $t$ & $\mathrm{p}$ & \\
\hline \multicolumn{10}{|l|}{ Location: HPL } \\
\hline Medusa abundance & Medusa occurrence & 14 & 0.23 & 3.72 & 0.002 & -0.62 & -0.22 & 0.83 & 0.50 \\
\hline SST & SST & 23 & 1.13 & 14.71 & $<0.001$ & -3.52 & -1.93 & 0.07 & 0.90 \\
\hline Salinity & Salinity & 23 & 0.45 & 8.62 & $<0.001$ & 7.00 & 8.50 & $<0.001$ & 0.76 \\
\hline \multicolumn{10}{|l|}{ Location: CBL } \\
\hline Medusa abundance & Medusa occurrence & 23 & 0.09 & 5.32 & $<0.001$ & -0.89 & -1.45 & 0.16 & 0.55 \\
\hline SST & SST & 23 & 1.02 & 12.73 & $<0.001$ & -0.28 & -0.15 & 0.88 & 0.88 \\
\hline Salinity & Salinity & 23 & 1.32 & 8.06 & $<0.001$ & -6.50 & -2.37 & 0.03 & 0.74 \\
\hline
\end{tabular}
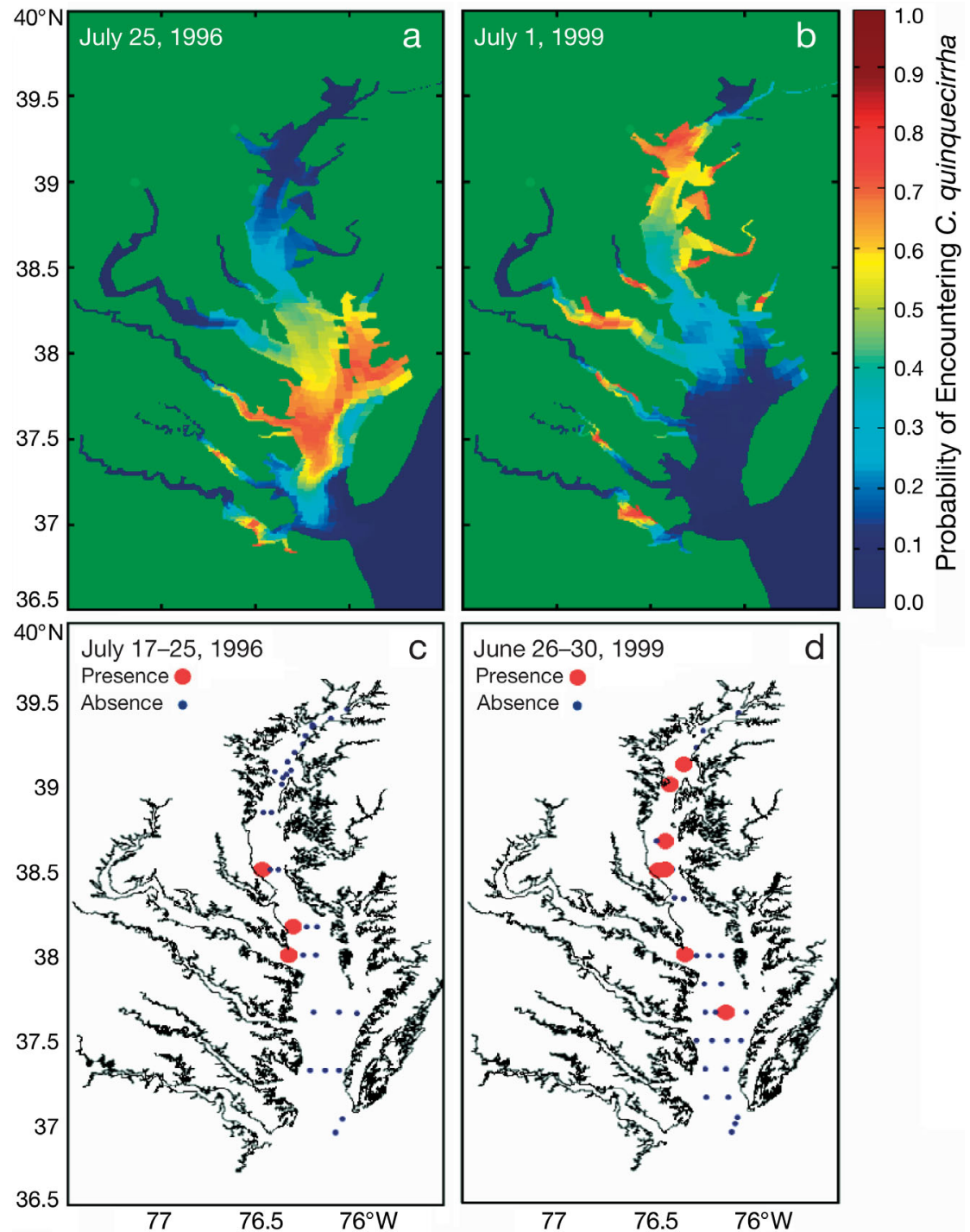

Fig. 10. Chrysaora quinquecirrha. Probability of medusa occurrence in surface waters of the Chesapeake Bay on (a) July 25, 1996, on (b) July 1, 1999, and (c,d) in situ observations from these nowcast periods. Large dots indicate medusa presence; small dots indicate medusa absence. In situ observations were collected by the Trophic Interactions in Estuarine Systems (TIES) program dusae. Below, we summarize what is known about effects of temperature and salinity on C. quinquecirrha and discuss mechanisms that may control the medusa distribution and abundance in Chesapeake Bay, and how these factors relate to the constructed habitat models.

\section{Effects of temperature and salinity on Chrysaora quinquecirrha polyps and ephyrae}

The perennial polyp stage of Chrysaora quinquecirrha, which asexually buds more polyps and produces new medusae (ephyrae) by strobilation, responds dramatically to different temperatures and salinities. Laboratory studies on polyps from Chesapeake Bay indicate that strobilation occurs after prolonged chilling and rewarming when temperatures reach $17^{\circ} \mathrm{C}$ in the spring (Loeb 1972). Further experiments conducted on polyps using combinations of temperature $\left(15,20,25^{\circ} \mathrm{C}\right)$ and salinity $(5,10,15,20,25,30,35)$ showed that cool temperature delay the onset of strobilation and that ephyra and polyp production were significantly reduced at both low $(\leq 10)$ and high $(\geq 25)$ salinities (Purcell et al. 1999). Warmer (i.e. summer) temperatures increased the number of ephyrae produced, but effects were significant only at high salinities $(25,30)$. These experimental results agree with our weekly bay-wide medusa predictions, which show temperature influencing 

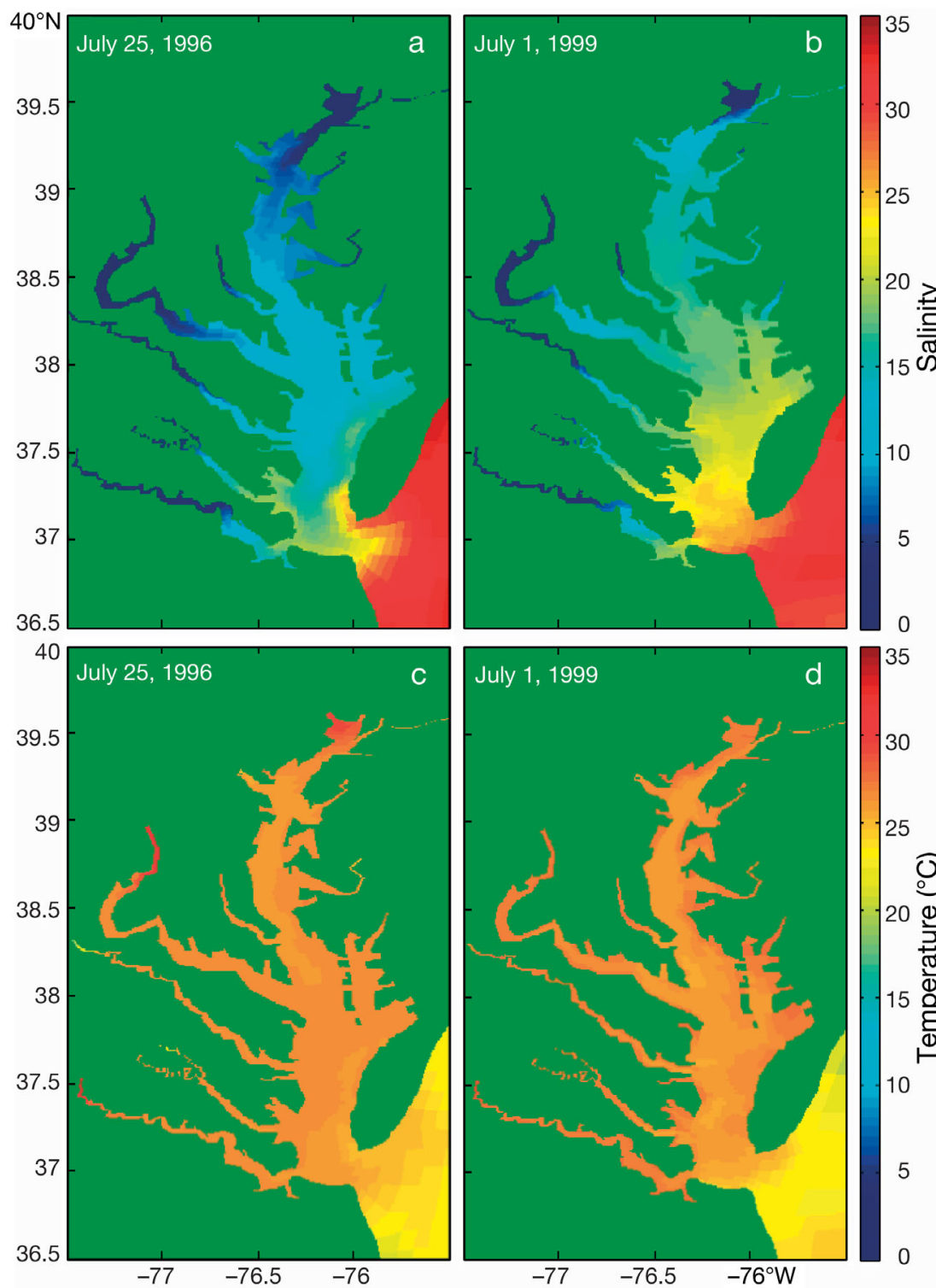

Fig. 11. (a,b) Surface salinity and (c,d) sea-surface temperature in Chesapeake Bay predicted by the hydrodynamic model Curvilinear Hydrodynamics in 3-Dimensions (CH3D) for the dates (a,d) July 25, 1996 and (b,d) July 1, 1999

when medusae appear in the bay, but salinity determining where medusae are first observed (i.e. within the optimal range for medusae, 10 to 16 ) (Hood et al. unpubl.). The mechanism underlying the negative effect of low salinity on strobilation may be related to the dependence of strobilation on iodide and the synthesis of thyroxin (Black \& Webb 1973, Silverstone et al. 1978). Iodide concentration is directly proportional to salinity (Luther \& Cole 1988), and thus, at very low salinities, iodide may be insufficient for strobilation (Purcell et al. 1999).

The physical tolerance of Chrysaora quinquecirrha may also be reflected in the spatial and temporal distributions of benthic polyps and free-swimming ephyrae.
Surveys of hard substrata indicate that polyps are limited to the middle regions of the mainstem bay and tributaries, where salinities typically range from 7 to 18 (Cargo \& Schultz 1966). Samples collected from early June through September, 1987, indicate that ephyrae were present in mesohaline tributaries in early June, but none were present after mid-August (Purcell 1992). Because strobilation is inhibited by high salinity (Purcell et al. 1999) and because salinity of the upper layer in Chesapeake Bay tends to increase as the summer progresses (CBP 2004), the production of ephyrae may diminish under the high salinity conditions of late summer. This hypothesis is supported by our model predictions and in situ observations which show medusa declines in August coincident with increasing salinity (Fig. 8). Although there is no mechanistic link to ephyrae in the model, declines in ephyra production may explain the empirical observation that medusa concentrations decline at high salinities, which is the basis of the model.

\section{Effects of temperature and salinity on Chrysaora quinquecirrha medusae}

Temperature and salinity may also directly affect Chrysaora quinquecirrha medusae, resulting in changes in distribution and abundance of this species as these factors fluctuate. Medusae are tolerant of temperatures between 10 and $34.5^{\circ} \mathrm{C}$ and pulse most actively at $30^{\circ} \mathrm{C}$ (Gatz et al. 1973). Surface water temperatures in the mesohaline Chesapeake Bay (Stn CB4.3C) during August are on average $26.1 \pm 0.1 \mathrm{SE}$ (CBP 2004), providing favorable thermal conditions for the medusae. Model predictions and in situ observations indicate that medusa numbers begin to diminish in August before water temperatures cool (Fig. 8), suggesting that population declines observed near the end of the season are not driven entirely by changes in water temperature.

In Chesapeake Bay, Chrysaora quinquecirrha medusae occur in waters of $\geq 5$ and $\leq 25$ salinity (Fig. 6 our paper, Cargo \& Schultz 1967). The lower salinity limit is most likely related to the inability of the medusae to regulate ions or maintain buoyancy at salinities $\leq 5$ 
(Wright \& Purcell 1997). It is not known what limits the medusae at salinities $>25$. This limitation is surprising because this species also occurs in the more saline waters of the US Atlantic and Gulf Coasts (Mayer 1910, Kramp 1961, Bayha 2005); however, the polyps in these oceanic populations may have very different responses to salinity and temperature (Purcell et al. 1999). These populations, which appear to differ physiologically, were indistinguishable genetically (Bayha 2005). C. quinquecirrha medusae increase the frequency of vertical movement when prey are present (Matanoski et al. 2001), presumably to maintain their position in a patch of prey; the medusae also show negative phototaxis (Schuyler \& Sullivan 1997). Thus, it is possible that the medusae employ vertical migration that exploits vertical stratification of the water column to maintain their populations in the mesohaline portion of the estuaries. In this scenario, medusae are effectively 'choosing' to remain in a specific saline and thermal regime. Mortality would probably be low during the summer months when medusae could sound to avoid unfavorably high temperatures and low salinities near-surface; however, mortality may increase in fall when the cooling water column mixes, and no refuge remains at depth.

Production of Chrysaora quinquecirrha medusae is also influenced by physical factors. Medusa egg production rates are greater in warmer temperatures $\left(20,25,30^{\circ} \mathrm{C}\right.$ ) than at $15^{\circ} \mathrm{C}$ (Asplen \& Purcell unpubl.). Warmer temperatures may allow C. quinquecirrha and other scyphomedusae to have longer and more prolific reproductive seasons, and to achieve larger populations (Purcell 2005). However, Chesapeake Bay medusa abundance in any given year showed little correlation with spawning success in the previous summer or with abundance of polyps in the fall (Cargo \& King 1990), indicating that the standing stock of C. quinquecirrha in the preceding year does not have a significant influence on medusa abundance.

\section{Predicting Chrysaora quinquecirrha medusa occurrence and distribution}

Our models and associated nowcasting/hindcasting system provide insight into the factors that control the temporal and spatial variability of Chrysaora quinquecirrha medusae in the Chesapeake Bay because it allows for the examination of inter-annual and seasonal variability in medusa distribution and abundance. Maps of the likelihood of medusa occurrence routinely generated by our system illustrate the evolution of the bloom through space and time; the patterns of medusa distributions can also be examined with respect to environmental factors in order to examine the timing of appearance and disappearance of medusae. For example, during very wet years (i.e. high precipitation and river discharge), the medusa bloom develops late in the season and is restricted to the lower mainstem Bay (Fig. 10a,c). By contrast, during years with average or below-average rainfall, medusae appear earlier in the season and are located in the upper mainstem Bay and tributaries (Fig. 10b,d). Our results also indicate that temperature and salinity have varying effects on the spatial distribution of medusae. In summer, salinity, which has a strong north-south gradient (Fig. 11a,b), is important in predicting where medusae are found in the bay (Fig. 10). By contrast, mid-summer surface temperature is uniform throughout Chesapeake Bay and has little apparent effect on the spatial distribution of $C$. quinquecirrha medusae (Figs. $10 \& 11 \mathrm{c}, \mathrm{d}$ ).

Our models, which employ temperature and salinity, predict the presence/absence and potential concentration of Chrysaora quinquecirrha medusae with reasonable accuracy (Figs. 5-10, Tables 3 \& 4); however, comparison of weekly hindcasts and observations indicates that the likelihood of occurrence model predicts the peak of the medusa bloom well, but the model is less accurate in predicting the presence of medusae at the beginning and end of the bloom (Fig. 8a,b). The medusa predictions are not improved by using observed sea-surface temperature and salinity to force the likelihood of occurrence model (Fig. 8a,b) because the physical parameters predicted by the hydrodynamic model track observed values in the bay (Figs. 8c-f \& 9, Table 4). The predictive ability of the model could probably be improved by incorporating additional factors known to affect jellyfish populations. For example, stream flow (Cargo \& King 1990), water depth, wind speed, and light (Purcell \& Decker 2005) may influence the abundance of $C$. quinquecirrha medusae in this system. In addition, zooplankton abundance in the spring could affect medusa populations; laboratory studies indicate that production of ephyrae (young medusae) increases with increasing prey availability (Purcell et al. 1999). We are unable to make mechanistic linkages of environmental conditions with the ephyra and polyp stages because in situ data on these forms are extremely limited. Inclusion of these stages would most likely improve the predictive ability of the models because there are potential temporal and spatial connections between where the medusae are produced by benthic polyps and where they are sampled by the net.

The habitat models and accompanying Chrysaora quinquecirrha medusa nowcasting system can be used as a scientific tool to provide a better understanding of in situ variability of medusa population arising from natural and anthropogenically induced changes in their 
habitat. Because C. quinquecirrha medusae are important predators of early life stages of fish and their zooplankton prey, fluctuations in jellyfish populations could have profound effects on the plankton food web and the production of harvestable species that utilize resources at similar trophic levels. The habitat models developed in this study can be used to quantify how changes in the medusa populations might affect ecosystem structure, particularly finfish production, in the bay. Similarly, the models can be employed to examine changes in the production and distribution of $C$. quinquecirrha medusae in relation to climate change, which has the potential to influence temperature and salinity regimes in estuaries worldwide (e.g. Kennedy et al. 2002), and how this might affect fisheries. Because the effects of climate change in estuaries may occur earlier and be more profound than in the open ocean (Kennedy et al. 2002), C. quinquecirrha may be a harbinger of the effects of climate change on coastal ecosystems. The habitat models and nowcasting system have improved understanding of the factors that influence blooms of gelatinous predators and can potentially be used to determine appropriate fisheries and management plans for the Chesapeake ecosystem.

Acknowledgements. We thank D. L. Breitburg and E. D. Houde for contributing their medusa and environmental data to this effort. Reviews by 3 anonymous reviewers and statistical consulting by F. Farach substantially improved earlier drafts of this manuscript. We are grateful to E. M. SeltzerHamilton for resuming D. G. Cargo's jellyfish counts along the Chesapeake Biological Laboratory (CBL) pier and we dedicate this paper to both of their memories. Funding for the data used in this study was provided by National Oceanic and Atmospheric Administration (NOAA) grants NA86AA-DSG006 and NA890AA-D-SG063 to the University of Maryland Sea Grant Program and by National Science Foundation grant DEB-9412113 to the Trophic Interactions in Estuarine Systems (TIES) group and by OCE-96336707 to J.E.P. This study was supported and monitored by the Office of Research and Applications of NOAA under Contracts DG133E-02-SE0247 and DG133E-03-SE-0862. Additional support was provided through grants from NOAA (NA04NOS4780265) to M.B.D, R.R.H, C.W.B, T.F.G and J.E.P and from Maryland Sea Grant Project Development to R.R.H. C.W.B. is an employee of NOAA and the views, opinions, and findings contained in this paper are his and should not be construed as an official National Oceanic and Atmospheric Administration or US Government position, policy, or decision.

\section{LITERATURE CITED}

Agresti A (1990) Categorical data analysis. John Wiley \& Sons, New York

Anderson PJ, Piatt JF (1999) Community reorganization in the Gulf of Alaska following ocean climate regime shift. Mar Ecol Prog Ser 189:117-123

Arai MN (2001) Pelagic coelenterates and eutrophication: a review. Hydrobiologia 45:69-87

Baird D, Ulanowicz RE (1989) The seasonal dynamics of the Chesapeake Bay ecosystem. Ecol Monogr 59:329-364
Bayha K (2005) The molecular systematics and population genetics of four coastal ctenophores and scyphozoan jellyfish of the US Atlantic and Gulf of Mexico. PhD dissertation, University of Delaware, Newark, DE

Black RE, Webb KL (1973) Metabolism of ${ }^{131} \mathrm{I}$ in relation to strobilation in Chrysaora quinquecirrha (Scyphozoa). Comp Biochem Physiol 45A:1023

Brodeur RD, Mills CE, Overland JE, Walters GE, Schumacher JD (1999) Evidence for a substantial increase in gelatinous zooplankton in the Bering Sea, with possible links to climate change. Fish Oceanogr 8:296-306

Brown CW, Hood RR, Li Z, Decker MB, Gross T, Purcell, J, Wang $H$ (2002) Forecasting system predicts presence of sea nettles in Chesapeake Bay. Eos Trans Am Geophys Union 83(30):321, 325-326

Cargo DG, King DR (1990) Forecasting the abundance of the sea nettle, Chrysaora quinquecirrha, in the Chesapeake Bay. Estuaries 13:486-491

Cargo DG, Schultz LP (1966) Notes on the biology of the sea nettle, Chrysaora quinquecirrha, in Chesapeake Bay. Chesapeake Sci 7:95-100

Cargo DG, Schultz LP (1967) Further observations on the biology of the sea nettle and jellyfishes in Chesapeake Bay. Chesapeake Sci 8:209-220

CBP (Chesapeake Bay Program) (2004) Water quality database design and data dictionary. US Environmental Protection Agency, Chesapeake Bay Program Office, Annapolis, MD

Cohen J (1960) A coefficient of agreement for nominal scales. Educ Psychol Measurement 20:37-46

Feigenbaum D, Kelly M (1984) Changes in the lower Chesapeake Bay food chain in presence of the sea nettle Chrysaora quinquecirrha (Scyphomedusa). Mar Ecol Prog Ser 19:39-47

Gatz AJ, Kennedy VS, Mihursky JA (1973) Effects of temperature on activity and mortality of the scyphozoan medusa, Chrysaora quinquecirrha. Chesapeake Sci 14:171-180

Graham WM, Martin DL, Felder DL, Asper VL, Perry HM (2003) Ecological and economic implications of a tropical jellyfish invader in the Gulf of Mexico. Biol Invasions 5: 53-69

Hay SJ, Hislop JRG, Shanks AM (1990) North Sea scyphomedusae: summer distribution, estimated biomass and significance particularly for 0-group gadoid fish. Neth J Sea Res 25:113-130

Hosmer DW, Lemeshow S (2000) Applied logistic regression. John Wiley \& Sons, New York

Kelly NM, Fonseca M, Whitfield P (2001) Predictive mapping for management and conservation of seagrass beds in North Carolina. Aquat Conserv 11:437-451

Kennedy VS, Twilley RR, Kleypas JA, Cowan JH, Hare SR (2002) Coastal and marine ecosystems and global climate change: potential effects on US resources. Report for the Pew Center on Global Climate Change, Arlington, VA

Kramp P (1961) Synopsis of the medusae of the world. J Mar Biol Assoc UK 40:1-469

Landis JR, Koch GG (1977) The measurement of observer agreement for categorical data. Biometrics 45:255-268

Loeb MJ (1972) Strobilation in the Chesapeake Bay sea nettle Chrysaora quinquecirrha 1. The effects of environmental temperature changes on strobilation and growth. J Exp Zool 180:279-292

Luther GW, Cole H (1988) Iodine speciation in Chesapeake Bay waters. Mar Chem 24:315-325

Matanoski JC, Hood RR, Purcell JE (2001) Characterizing the effect of prey on swimming and feeding efficiency of the scyphomedusa Chrysaora quinquecirrha. Mar Biol 139: 191-200 
Matsueda N (1969) Presentation of Aurelia aurita at thermal power station. Bull Mar Biol Stn Asamushi 13:197-191

Matsumura K, Kamiya K, Yamashita K, Hayashi F and 5 others (2005) Genetic polymorphism of the adult medusae invading an electric power station and wild polyps of Aurelia aurita in Wakasa Bay, Japan. J Mar Biol Assoc UK 85:563-568

Mayer AG (1910) Medusae of the world, Vol III. The scyphomedusae. Carnegie Institution, Washington, DC

Mills CE (2001) Jellyfish blooms: Are populations increasing globally in response to changing ocean conditions? Hydrobiologia 451:55-68

Odom RH, Ford WM, Edwards JW, Stihler CW, Menzel JM (2001) Developing a habitat model for the endangered Virginia northern flying squirrel (Glaucomys sabrinus fuscus) in the Allegheny Mountains of West Virginia. Biol Conserv 99:245-252

Parsons TR, Lalli CM (2003) Jellyfish population explosions: revisiting a hypothesis of possible causes. La Mer 40: $11-121$

Purcell JE (1992) Effects of predation by the scyphomedusan Chrysaora quinquecirrha on zooplankton populations in Chesapeake Bay, USA. Mar Ecol Prog Ser 87:65-76

Purcell JE (2005) Climate effects on formation of jellyfish and ctenophore blooms. J Mar Biol Assoc UK 85:461-476

Purcell JE, Cowan JH, Jr (1995) Predation by the scyphomedusan Chrysaora quinquecirrha on Mnemiopsis leidyi ctenophores. Mar Ecol Prog Ser 129:63-70

Purcell JE, Decker MB (2005) Effects of climate on relative predation by scyphomedusae and ctenophores on copepods in Chesapeake Bay during 1987-2000. Limnol Oceanogr 50:376-387

Purcell JE, Nemazie DA, Dorsey SE, Houde ED, Gamble JC (1994a) Predation mortality of bay anchovy Anchoa mitchilli eggs and larvae due to scyphomedusae and ctenophores in Chesapeake Bay. Mar Ecol Prog Ser 114: $47-58$

Purcell JE, White JR, Roman MR (1994b) Predation by gelatinous zooplankton and resource limitation as potential controls of Acartia tonsa copepod populations in Chesapeake Bay. Limnol Oceanogr 39:263-278

Purcell JE, White JR, Nemazie DA, Wright DA (1999) Temper-

Editorial responsibility: Kenneth Sherman (Contributing Editor), Narragansett, Rhode Island, USA ature, salinity and food effects on asexual reproduction and abundance of the scyphozoan Chrysaora quinquecirrha. Mar Ecol Prog Ser 180:187-196

Purcell JE, Graham WM, Dumont H (eds) (2001) Jellyfish blooms: ecosystem and societal importance. Developments in hydrobiology 155. Kluwer Academic Publishers, Dordrecht

Rajagopal S, Nair KVK, Azariah J (1989) Some observations on the problem of jelly fish ingress in a power station cooling system at Kalpakkam, east coast of India. Mahasagar 22:151-158

Schultz LP, Cargo DG (1969) Sea nettle barriers for bathing beaches in upper Chesapeake Bay. Ref. No. 69-58, Natural Resources Institute, University of Maryland, College Park, MD

Schultz LP,Cargo DG (1971) The sea nettle of Chesapeake Bay. Education Series No. 93. Natural Resources Institute, University of Maryland, College Park, MD

Schuyler D, Sullivan BK (1997) Light responses and diel migration of the scyphomedusa Chrysaora quinquecirrha in mesocosms. J Plankton Res 19:1417-1428

Sheng YP (1987) On modeling three-dimensional estuarine and marine hydrodynamics. In: Nihoul JCJ, Jamart BM (eds) Three-dimensional models of marine and estuarine dynamics. Elsevier, Amsterdam, p 35-54

Silverstone M, Galton VA, Ingbar SH (1978) Observations concerning the metabolism of iodine by polyps of Aurelia aurita. Gen Comp Endocrinol 34:132-140

Sullivan BK, Van Keuren D, Claucy M (2001) Timing and size of blooms of the ctenophore Mnemiopsis leidyi in relation to temperature in Narragansett Bay, RI. Hydrobiologia 451:113-120

Wang HV, Johnson BJ (2000) Validation and application of the second generation three dimensional hydrodynamic model of Chesapeake Bay. Water Qual Ecosys Modeling 1: 51-90

Wright DA, Purcell JE (1997) Effect of salinity on ionic shifts in mesohaline scyphomedusae, Chrysaora quinquecirrha. Biol Bull 192:332-339

Yasuda T (1988) Unusually gregarious occurrences of jellyfishes in Japanese waters. Saishu to Shiiku 50:338-346 (in Japanese)

Submitted: October 3, 2005; Accepted: July 21, 2006

Proofs received from author(s): December 11, 2006 